\title{
Treatment effects of R-appliance and Anterior Inclined Bite Plate in Class II, Division I malocclusion
}

\author{
Rahman SHOWKATBAKHSH ${ }^{1}$, Shahin Emami MEYBODI ${ }^{2}$, Abdolreza JAMILIAN ${ }^{3}$, Seyyed Amir Reza Fatahi MEYBODI ${ }^{4}$, \\ Elham Morshedi MEYBODI ${ }^{5}$
}

\author{
1-Associate Professor, Director of Orthognathic Surgery Fellowship, Orthodontics Department, Shahid Beheshti University of Medical Sciences, Tehran, Iran. \\ 2- Associate Professor, Orthodontics Department, Dental Branch, Islamic Azad University, Tehran, Iran. \\ 3- Associate Professor, Fellow of Orthognathic Surgery, Orthodontics Department, Dental Branch, Islamic Azad University, Tehran, Iran. \\ 4- Orthodontic Department, Tehran University of Medical Sciences, Tehran, Iran. \\ 5- DDS, Private practice, Tehran, Iran.
}

Corresponding address: Prof. Abdolreza Jamilian - № 2713 - Jam Tower - Valiasr St. - Tehran - 1966843133 - Phone: 00982122011892 - Fax: 00982122022215 - e-mail: info@jamilian.net

Received: November 05, 2009 - Modification: May 02, 2010 - Accepted: October 26, 2010

\section{ABSTRACT}

\begin{abstract}
$\mathrm{O}$ bjectives: The purpose of this study was to compare the effects of a differently designed functional appliance (R-appliance) and the Anterior Inclined Bite Plate (AIBP) in Class II Division I (Cl II Div I) cases. Material and Methods: Fifty patients (28 girls, 22 boys) were chosen for the study: 25 patients (13 girls, 12 boys) with mean age of $10.4 \pm 0.8$ years were treated with R-appliance for $11 \pm 2$ months, the other 25 patients (15 girls, 10 boys) with mean age of $9 \pm 1.2$ years were treated with AIBP for $10 \pm 2$ months. All patients had CI II Div I malocclusion due to mandibular deficiency. Lateral cephalograms were analyzed at the beginning $\left(T_{1}, T_{1}\right)$ and end of the study $\left(T_{2}, T_{2}\right)$. Results: Paired T-test showed that SNB had a significant increase in both groups. The same test revealed that IMPA was reduced in R-appliance for $3.1 \pm 4.7(p<0.01)$, but it was increased for $0.1 \pm 5.1(p<0.9)$ in AIBP group. T-test showed that the inter-group difference of IMPA was statistically significant $(p<0.05)$. SNA showed an increase in both groups $(p<0.9)$. Ar-B and Ar-Pog showed an increase in both groups and the differences between them were statistically significant. Conclusions: Mandibular advancement was achieved in both groups, but R-appliance achieved this result without lingual tipping of lower incisors.
\end{abstract}

Key words: Functional orthodontic appliances. Removable orthodontic appliances. Angle Class II malocclusion. Growth.

\section{INTRODUCTION}

Class II malocclusion is a skeletal discrepancy that may be caused by maxillary protrusion, mandibular retraction must be replaced by retrusion. Class II subdivision malocclusions can be corrected through a variety of treatment protocols ${ }^{13}$. Different removable functional appliances have been used in growing patients to treat this malocclusion $5,6,8,19,28,30$. Several studies have described positive effects with various functional appliances and have focused on their effects on skeletal and dental structures ${ }^{1,2,4,11,15,16,17,18,23,25}$. However, functional appliances restrict the growth of the maxilla $3,10,14,21,22,26,27$ and cause labial tipping of lower incisors $3,20,29$. Restriction of the maxilla and proclination of lower anterior incisors are the main disadvantages of such appliances.

Functional appliances have shown a significant diversity in design, which could easily affect their acceptance by the patients ${ }^{9}$.

A recently introduced appliance named "the R-appliance"12 is believed to cause no labial tipping of the lower incisors. However, there is another functional appliance named Anterior Inclined Bite Plane (AIBP), which is smaller and more comfortable for patients than the R-appliance.

As no comparisons between these two promising 
appliances were found in the literature, the aim of this study was to evaluate dentoskeletal changes achieved by the R-appliance ${ }^{12}$ in comparison with AIPB in Class II Division I patients in the mixed dentition phase.

\section{MATERIAL AND METHODS}

This study consisted of 50 patients ( 22 boys, 28 girls) who were randomly assigned to two groups using a standard random number table. All subjects had to meet the following inclusion criteria:

1- $A N B>4^{\circ}, S N B<78^{\circ}$, overjet $>5 \mathrm{~mm}$ in the initial lateral cephalograms;

2- No syndromic or medically compromised patients;

3- No surgical intervention;

4- No use of other appliances before or during the period of functional treatment; $\mathrm{SN})$;

5- Normal growth pattern of the mandible (MP-

6- Symmetric relationship between maxilla and mandible.

Twenty-five patients (13 girls, 12 boys) were randomly chosen to be treated with the R-appliance (Figures 1 and 2 ). The mean age was $10.4 \pm 0.8$ years and the mean treatment time was $11 \pm 2$ months. Patients were instructed to wear the R-appliances 18 hours a day. The R-appliance is a tooth and tissue borne appliance. It consists of buccal and lingual shields, which are connected to each other through the occlusal clearance during bite construction. These shields are extended to the distal of first molars and cover the buccal and lingual region and the depth of vestibule; however, the lingual shield should be fabricated with less undercut relief. This relief must be done as minimally as possible to allow appliance settlement easily. The right and left lower lingual shields are connected and reinforced with a heavy archwire to withstand the load of muscular activity ( $1 \mathrm{~mm}$ diameter). A heavy wire (1 $\mathrm{mm}$ diameter), which acts as a tongue bow, is positioned posteriorly to connect the right and left acrylic part on the palatal area in order to reinforce the appliance. Labial bow is constructed by a $0.7 \mathrm{~mm}$ wire extended from canine to canine with vertical loop on the canine area. In this group the construction bites were taken when upper and lower anterior teeth were brought edge to edge with 2 to $3 \mathrm{~mm}$ posterior clearance. Lateral cephalograms of R-appliance group were taken in centric occlusion at the onset $\left(T_{1}\right)$ and at the completion $\left(T_{2}\right)$ of functional treatment.

The AIBP group consisted of 25 patients (15 girls, 10 boys) with mean age of $9 \pm 1.2$ years, who were treated with AIBP. The treatment duration was $10 \pm 2$ months. The patients were instructed to wear the AIBP for 18 hours a day. This appliance consists of a simple Hawley appliance with an inclined plane in the anterior region which causes the mandible to have forward position during closure (Figure 5). Lateral cephalograms of AIBP group were taken at the onset $\left(T_{1}\right)$ and after 18 months of observation $\left(\mathrm{T}_{2}\right)$.

SNA, SNB, ANB, MP-SN, Ar-A (the distance between articulare to point $A$ ), Ar- $B$, (the distance

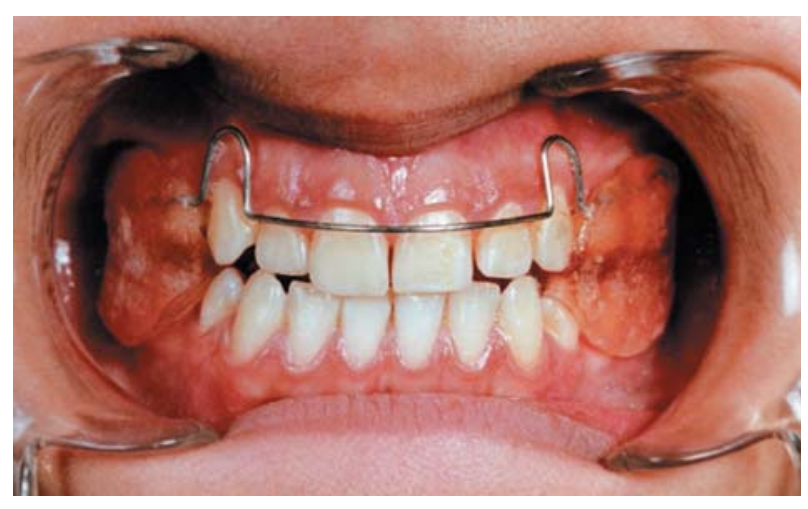

Figure 1- R-appliance in patient's mouth

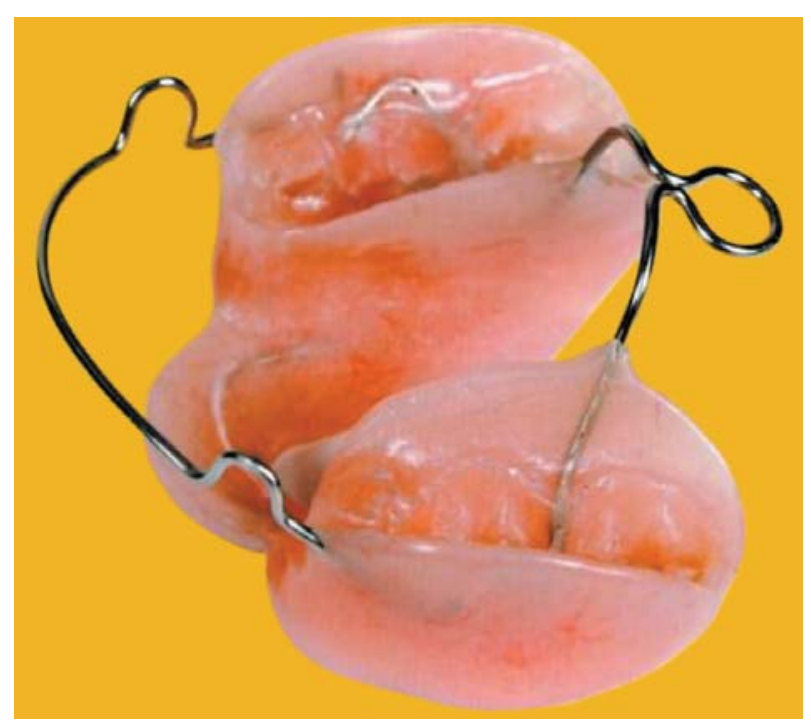

Figure 2- R-appliance

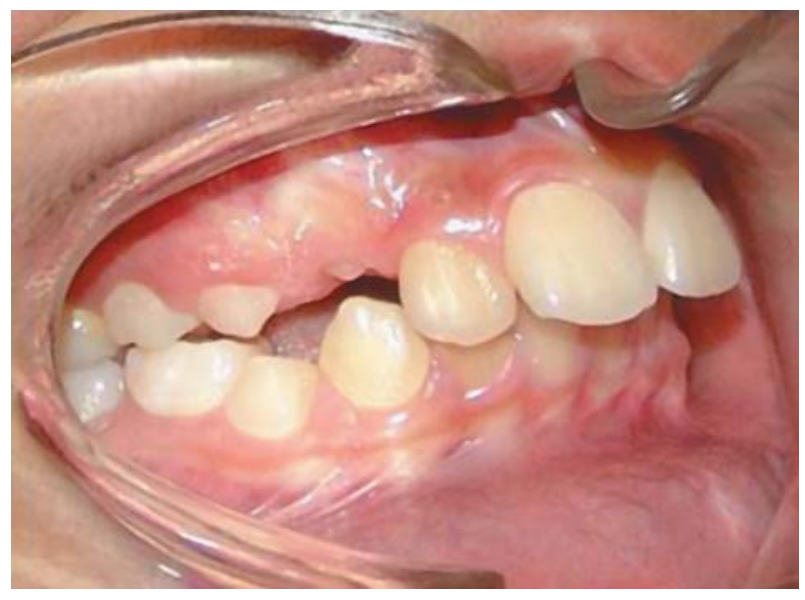

Figure 3- Pretreatment photograph of the patient 


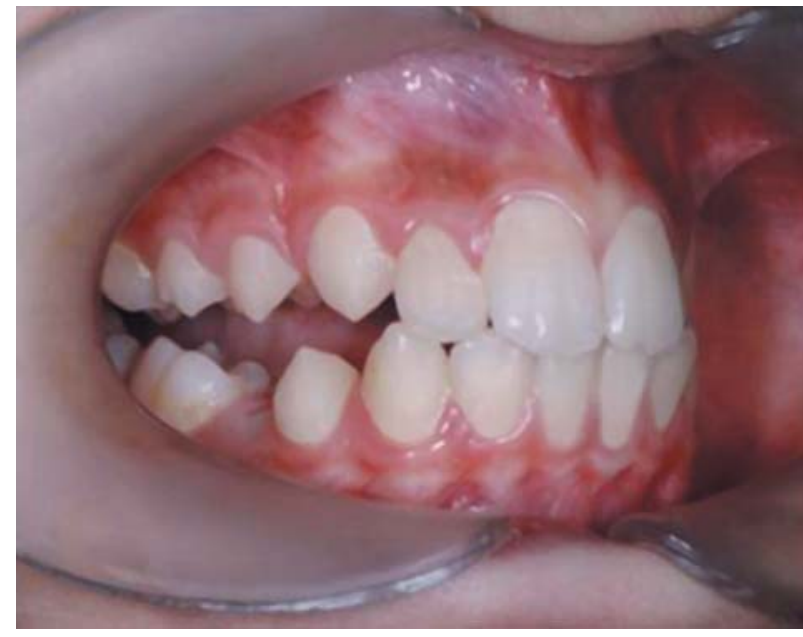

Figure 4- Posttreatment photograph of the same patient of Figure 3 treated by R-appliance

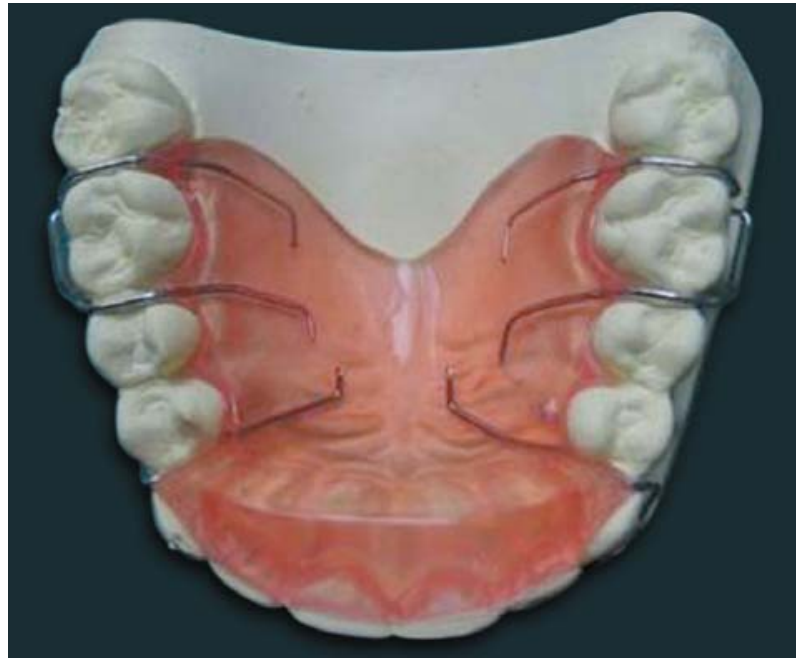

Figure 5- Anterior Inclined Bite Plate

Table 1- Pretreatment and post treatment measurements of R-appliance group

\begin{tabular}{ccccc}
\hline Cephalometric Measures & $\begin{array}{c}\text { Before Treatment } \\
\text { Mean } \pm \text { SD }\end{array}$ & $\begin{array}{c}\text { After Treatment } \\
\text { Mean } \pm \text { SD }\end{array}$ & $\begin{array}{c}\text { Changes } \\
\text { Mean } \pm S D\end{array}$ & P Value \\
\hline SNA & $78.7 \pm 3.7$ & $79.3 \pm 3.9$ & $0.6 \pm 1.7$ & 0.1 \\
SNB & $72.3 \pm 2.9$ & $75 \pm 3.2$ & $2.7 \pm 1.6$ & 0.001 \\
ANB & $6.7 \pm 1.7$ & $4.2 \pm 1.3$ & $-2.5 \pm 1.3$ & 0.001 \\
MP-SN & $36.1 \pm 5.7$ & $36.8 \pm 6.4$ & $0.7 \pm 2$ & 0.1 \\
Ar-A & $85.9 \pm 6.2$ & $87.6 \pm 5.9$ & $1.7 \pm 3.2$ & 0.02 \\
Ar-B & $90.9 \pm 5.5$ & $97 \pm 6$ & $6.1 \pm 3.6$ & 0.001 \\
Ar-Pog & $99.2 \pm 7.1$ & $106.6 \pm 6.9$ & $7.4 \pm 4.3$ & 0.001 \\
\hline IMPA & $101.1 \pm 5.3$ & $98 \pm 5.9$ & $-3.1 \pm 4.7$ & 0.01 \\
\hline to SN & $105.6 \pm 5.6$ & $97.4 \pm 5.9$ & $-8.2 \pm 6.5$ & 0.001 \\
\hline
\end{tabular}

Table 2- Pretreatment and posttreatment measurements of Anterior Inclined Bite Plate (AIBP) group

\begin{tabular}{lcccc}
\hline \multicolumn{1}{c}{ Cephalometric Measures } & $\begin{array}{c}\text { Before Treatment } \\
\text { Mean } \pm \text { SD }\end{array}$ & $\begin{array}{c}\text { After Treatment } \\
\text { Mean } \pm \text { SD }\end{array}$ & $\begin{array}{c}\text { Changes } \\
\text { Mean } \pm \text { SD }\end{array}$ & P Value \\
\hline SNA & $77.6 \pm 2.8$ & $78.1 \pm 2.8$ & $0.5 \pm 1.8$ & 0.2 \\
\hline SNB & $72.8 \pm 3.5$ & $74.3 \pm 3.6$ & $1.5 \pm 1.7$ & 0.001 \\
\hline ANB & $6 \pm 1.1$ & $4.5 \pm 1.2$ & $-1.5 \pm 0.9$ & 0.001 \\
\hline MP-SN & $36.5 \pm 6$ & $36.1 \pm 6.2$ & $-0.4 \pm 1.6$ & 0.3 \\
\hline Ar-A & $86.5 \pm 5$ & $87.7 \pm 4.8$ & $1.2 \pm 3$ & 0.1 \\
\hline Ar-B & $90.9 \pm 5.7$ & $93.9 \pm 6$ & $3 \pm 3.8$ & 0.001 \\
\hline Ar-Pog & $97.6 \pm 6.4$ & $101.5 \pm 6.2$ & $3.9 \pm 4.3$ & 0.001 \\
\hline IMPA & $97.2 \pm 11$ & $97.3 \pm 10$ & $0.1 \pm 5.1$ & 0.9 \\
\hline 1 to SN & $102.7 \pm 5.5$ & $97.2 \pm 8.3$ & $-5.5 \pm 9.8$ & 0.01 \\
\hline
\end{tabular}

between articulare to point B), Ar-Pog (the distance between articulare to pogonion), 1 to SN (angle between long axis upper central incisor and anterior cranial base), and IMPA (angle between long axis lower central incisor and mandibular plane) were measured in $T_{1}, T_{2}, T_{1}$ and $T_{2}$. All measurements were made manually by one investigator. Twenty random cephalograms were selected and measured after 2 weeks, and there was no statistically significant difference among them.

Paired T-test was used for intra-group evaluation and the T-test was used for intergroup evaluation. 
Statistical significance was set at $p<0.05$. The magnification factor of cephalograms was standardized at 7\%. Statistical software of SPSS, Version 16 was used in order to examine the data.

\section{RESULTS}

Paired T-test showed that in R-appliance group SNB, Ar-A, Ar-B, and Ar-Pog increased significantly. ANB showed a decrease of $2.5^{\circ} \pm 1.3^{\circ}(p<0.001)$. The change of SNA was non-significant. IMPA showed a decrease of $3.1^{\circ} \pm 4.7^{\circ}(p<0.01)$ (Table 1$)$.

The same tests showed that in AIBP group SNB, Ar-B, and Ar-Pog had a significant increase. ANB decreased for $1.5 \pm 0.9(p<0.001)$. SNA had a nonsignificant increase and IMPA was increased for $0.1^{\circ} \pm 5.1^{\circ}(p<0.9)$ (Table 2$)$.

In intergroup evaluations T-test revealed that both SNA differences were nonsignificant; however, SNB, Ar-B and Ar-Pog differences were statistically significant. Same test showed that IMPA was decreased in R-appliance group, while it had an increase in AIBP group $(p<0.05)$ (Table 3$)$.

Figures 3 and 4 show the same patient before treatment and after R-appliance treatment.

Table 3- Comparison of R-appliance and Anterior Inclined Bite Plate (AIBP) group measurements

\begin{tabular}{lcrl}
\hline $\begin{array}{c}\text { Cephalometric } \\
\text { Measures }\end{array}$ & $\begin{array}{c}\text { AlBP } \\
\text { Mean } \pm \text { SD }\end{array}$ & $\begin{array}{c}\text { R-Appliance } \\
\text { Mean } \pm \text { SD }\end{array}$ & P Value \\
\hline SNA & $0.5 \pm 1.8$ & $0.6 \pm 1.7$ & 0.9 \\
SNB & $1.5 \pm 1.7$ & $2.7 \pm 1.6$ & 0.02 \\
\hline ANB & $-1.5 \pm 0.9$ & $-2.5 \pm 1.3$ & 0.01 \\
\hline MP-SN & $-0.4 \pm 1.6$ & $0.7 \pm 2$ & 0.05 \\
\hline Ar-A & $1.2 \pm 3$ & $1.7 \pm 3.2$ & 0.6 \\
\hline Ar-B & $3 \pm 3.8$ & $6.1 \pm 3.6$ & 0.01 \\
Ar-Pog & $3.9 \pm 4.3$ & $7.4 \pm 4.3$ & 0.01 \\
IMPA & $0.1 \pm 5.1$ & $-3.1 \pm 4.7$ & 0.05 \\
\hline 1 to SN & $-5.5 \pm 9.8$ & $-8.2 \pm 6.5$ & 0.3 \\
\hline
\end{tabular}

\section{DISCUSSION}

This study showed that both R-appliance and AIBP could successfully improve mandibular deficiency without causing headgear effect. Ar-B and Ar-Pog were increased more in R-appliance compared with AIBP. Consequently, further remodeling was achieved in $\mathrm{R}$-appliance group. Lower incisors were flared in AIPB group, although they presented lingual tipping in R-appliance group. The maxilla did not show any restriction in either of the groups.

In order to get construction bite in R-appliance group the mandible was positioned anteriorly to achieve an edge to edge relationship parallel to the functional occlusal plane. The lingual shield of R-appliance was fabricated with less undercut relieve. This relief must be done as minimally as possible to allow appliance settlement easily. In order to avoid any potential trauma, all patients were recurrently instructed to move the mandible in forward position; However, the discomfort caused by no relieve in the lingual shield in R-appliance group, changed this compliance into an unconscious one in the long run. Due to activation of protractor muscles mandible would be kept in forward position and retractor muscles would not have any significant role to pull it back. This active protrusion has a favorable effect on the growth and remodeling of the mandible. In addition, this activation is effective in preventing headgear effect on maxillary complex and flaring of lower incisors. Mandibular closure might create excessive retracting force on the upper anterior teeth, which could be the rational reason for upper anterior lingual tipping during the treatment. In other words, the retracting force on the upper anterior takes place only at the beginning of mandibular closure. SNA might be decreased due to lingual tipping of upper incisors. However, the actual amount of SNA might be more than the resulted amount. Lingual tipping of the upper incisors can be corrected by re-torqueing, which will increase SNA.

Although R-appliance was successful in moving the mandible to a more forward position, it affected patient's speech and lateral jaw movement. Moreover, this appliance cannot be used in subjects with nasal obstruction. And patients do not easily adapt to this appliance because of its large size and unfixed position in the mouth. All these factors may lead to a decrease in patient's compliance. On the other hand, AIBP does not restrict the 3-dimensional mandibular movement and does not interfere with the regular physiological activity of oral cavity. These are great advantages for patients' cooperation. An ideal functional appliance should be comfortable to patient, allow jaw movement, leave room for the tongue, provide skeletal rather than dental effects, and should be such that it could be used in subjects with nasal obstruction ${ }^{24}$.

Treatment mechanisms of R-appliance and AIBP are basically different from each other. In AIBP, the proprioceptive organ of periodontal space should be stimulated by occlusal contact in swallowing cycle. The proprioceptive sensory feedback mechanism synchronizes muscular activity and provides a functional stimulus to the full expression of mandibular bone growth in active phase. Active forward movement of mandible reaches its highest amount during swallowing, which is approximately $17.5 \mathrm{~min}$ a day. The unfavorable cuspal contacts of 
distal occlusion obstruct normal forward movement of the mandible. Therefore, the mandible does not achieve its optimum genetic growth position. AIBP disoccludes the mandible from its lock position and eliminates the growth restriction and keeps moving the mandible forward in rest position.

One of the shortcomings of this study is that the treated groups were not compared to a control untreated group with natural growth and development.

\section{CONCLUSIONS}

The following conclusions can be drawn on the basis of the findings of this study:

1- R-appliance and AIBP will result in forward positioning of the mandible.

2- Both AIBP and R-appliance did not cause any headgear effect on the maxilla.

3- Unlike AIBP, R-appliance does not cause any proclination effect on the lower anterior teeth; moreover, it might even reduce the flaring of lower anterior incisors.

4- The smaller size of AIBP makes it more suitable for patients compared with R-appliance.

5- R-appliance showed to be more effective in mandibular advancement.

\section{REFERENCES}

1- Aelbers CM, Dermaut LR. Orthopedics in orthodontics: part I, fiction or reality - a review of the literature. Am J Orthod Dentofacial Orthop. 1996;110:513-9.

2- Bishara SE, Ziaja RR. Functional appliances: a review. Am J Orthod Dentofacial Orthop. 1989;95:250-8.

3- Clark WJ. Twin block functional therapy. $2^{\text {nd }}$ ed. Saint Louis: Mosby; 2002. p. 343-56.

4- Clark WJ. Twin block functional therapy: applications in dentofacial orthopaedics. London: Mosby-Wolfe; 1995. p. 45-6. 5- Clark WJ. The twin block technique. A functional orthopedic appliance system. Am J Orthod Dentofacial Orthop. 1988;93:1-18. 6- Ehmer U, Tulloch CJ, Proffit WR, Phillips C. An international comparison of early treatment of Class II/1 cases: skeletal effects of the first phase of a prospective clinical trial. J Orofac Orthop. 1999;60:392-408.

7- Emami MS, Jamilian A, Showkatbakhsh A. The effect of anterior inclined plane treatment on the dentoskeletal of Class II division 1 patients. J Indian Soc Pedod Prev Dent. 2007;25:130-2.

8- Ghafari J, Shofer FS, Jacobsson-Hunt U, Markowitz DL, Laster LL. Headgear versus functional regulator in the early treatment of Class II, division 1 malocclusion: a randomized clinical trial. Am J Orthod Dentofacial Orthop. 1988;113:51-61.

9- Graber TM, Neumann B. Removable orthodontic appliances. Philadelphia: WB Saunders; 1984. p. 198-356.

10- Hägglund $P$, Segerdal $S$, Forsberg CM. The integrated Herbst appliance-treatment effects in a group of adolescent males with Class II malocclusions compared with growth changes in an untreated control group. Eur J Orthod. 2008;30:120-7.
11- Jacobs T, Sawaengkit P. National Institute of Dental and Craniofacial Research efficacy trials of bionator Class II treatment: a review. Angle Orthod. 2002;72:571-5.

12- Jamilian A, Showkatbakhsh R, Kamali Z. R-appliance: a different design in functional therapy in Class II Division I malocclusion. Int J Orthod Milwaukee. 2009;20:11-14.

13- Janson M, Janson G, Sant'Ana E, Simão TM, Freitas MR. An orthodontic-surgical approach to Class II subdivision malocclusion treatment. J Appl Oral Sci. 2009;17:266-73.

14- Kerr WJS, TenHave TR, McNamara JA Jr. A comparison of skeletal and dental changes produced by function regulators (FR-2 and FR-3). Eur J Orthod. 1989:235-42.

15- Lohakare SS. Orthodontic removable appliances. New Delhi: Jaypee Brothers Medical Publishers; 2008. p. 46.

16- McDonagh S, Moss JP, Goodwin P, Lee RT. A prospective optical surface scanning and cephalometric and assessment of the effect of functional appliances on the soft tissues. Eur J Orthod. 2001;23:115-26.

17- McSherry PF, Bradley H. Class II correction - reducing patient compliance: a review of the available techniques. J Orthod. 2000;27:219-25.

18- Mills JR. The effect of functional appliances on the skeletal pattern. Br J Orthod. 1991;18:267-75

19- O'Brien K, Wright J, Conboy F, Sanjie Y, Mandall N, Chadwick $S$, et al. Effectiveness of treatment for Class II malocclusion with the Herbst or twin-block appliances: a randomized, controlled trial. Am J Orthod Dentofacial Orthop. 2003;124:128-37.

20- Pancherz $\mathrm{H}$. The mechanism of Class II correction in Herbst appliance treatment. A cephalometric investigation. Am J Orthod. 1982;82:104-13.

21- Pangrazio-Kulbersh V, Berger JL, Chermak DS, Kaczynski R, Simon ES, Haerian A. Treatment effects of mandibular anterior repositioning appliances on patients with Class II malocclusion. Am J Orthod Dentofacial Orthop. 2003;123:286-95.

22- Perillo L, Johnston LE Jr, Ferro A. Permanence of skeletal changes after function regulator (FR-2) treatment of patients with retrusive Class II malocclusions. Am J Orthod Dentofacial Orthop. 1996;109:132-9.

23- Petrovic A, Stutzmann J, Lavergne J, Shaye R. Is it possible to modulate the growth of the human mandible with a functional appliance? Int J Orthod. 1991;29:3-8.

24- Sari Z, Goyenc Y, Doruk C, Usumez S. Comparative evaluation of a new removable Jasper Jumper functional appliance vs. activator-headgear combination. Angle Orthod. 2003;73:286-93 25- Shen G, Hägg U, Darendeliler M. Skeletal effects of bite jumping therapy on the mandible - removable vs. fixed functional appliances. Orthod Craniofac Res. 2005;8:2-10.

26- Toth LR, McNamara JA Jr. Treatment effects produced by the twin-block appliance and the FR-2 appliance of Fränkel compared with an untreated Class II sample. Am J Orthod Dentofacial Orthop. 1999;116:597-609.

27- Trenouth MJ. Cephalometric evaluation of the twin-block appliance in the treatment of Class II Division 1 malocclusion with matched normative data. Am J Orthod Dentofacial Orthop. 2000; 117:54-9.

28- Tulloch JFC, Proffit WR, Phillips C. Influences on the outcome of early treatment for Class II malocclusion. Am J Orthod Dentofacial Orthop. 1997; 111:533-42.

29- Vargervik K, Harvold EP. Response to activator treatment in Class II malocclusions. Am J Orthod. 1985;88:242-51.

30- Wheeler TT, McGorray SP, Dolce C, Taylor MG, King GJ. Effectiveness of early treatment of Class II malocclusion. Am J Orthod Dentofacial Orthop. 2002;121:9-17. 